\title{
lodine Deficiency Disorders Continue to be a Problem in the Asia Pacific Region
}

\author{
Creswell J. Eastman \\ International Council for the Control of Iodine Deficiency Disorders (ICCIDD), Westmead, New South Wales, Australia
}

\begin{abstract}
lodine deficiency disorders (IDD) due to inadequate dietary iodine is one of the major non-communicable diseases yet to be eliminated from our world, particularly in the Asia Pacific region. There has been remarkable progress in reducing iodine deficiency over the past two decades, with 50 more countries declaring successful elimination mainly due to effective implementation of universal salt iodization (USI) programs. The most devastating — but often the least visibleeffect of IDD is damage to the central nervous system, causing a spectrum of impairment from mild loss of intelligence quotient (IQ), to severe, irreversible brain damage called neurological cretinism.

The majority of nations in the vast expanse of the Asia Pacific region, encompassing small Pacific island states to the most populous countries in the world, continue to suffer from the health and socio-economic consequences of IDD. Contrary to popular belief, IDD is not confined to remote mountainous regions and economically disadvantaged populations, but may also affect wealthy, industrialized societies such as Australia and New Zealand. Japan and China are examples of countries relatively free of IDD; the former because of a diet naturally rich in iodine, and the latter due to the implementation of a sustainable USI program. While USI is the preferred strategy for sustainable elimination of IDD, it is not always practicable. As such, countries need to consider other methods of iodine supplementation or food fortification.
\end{abstract}

Keywords: iodine deficiency, goitre, hypothyroidism

\section{INTRODUCTION}

The World Health Organization (WHO) has recently released updated global and country population statistics on the prevalence of iodine deficiency. ${ }^{1}$ In 2005, the World Health Assembly (WHA) resolved that member states should monitor and report the iodine nutrition status of their respective populations every 3 years. ${ }^{2}$ The new WHO global estimates of iodine status include statistics from 115 out of $193 \mathrm{WHO}$ member states and cover over $90 \%$ of the world's population of children. ${ }^{1}$ Overall, it is estimated that $30 \%$ of these children, numbering approximately 241 million, have inadequate iodine intake. More than half of these children come from Southeast Asia and Africa. In 2011, there were 30 known iodine deficient countries. This is a conservative figure as many smaller countries have not provided any data on which an assessment can be made.

The vast geographical expanse of Southeast Asia and the Pacific region-including more than 40 sovereign states ranging from tiny Pacific islands to some of the most populous nations on earth, such as India, Indonesia and China-poses a challenge in identifying and addressing the problems of IDD in this part of the world. Poverty and social disadvantage characterize many of these

\section{ISSN 0857-1074}

Printed in the Philippines

Copyright (C) 2012 by the JAFES

Received October 15, 2012. Accepted October 29, 2012. underdeveloped countries. While IDD most commonly coexists with poor social and economic development, geographic isolation and mountainous terrain, it is a myth that it is restricted to countries with such conditions. ${ }^{3}$ The United Nations Children's Fund (UNICEF) has estimated that there are more than 20 million babies born annually within the Asia Pacific region who are not protected from iodine deficiency. The majority of these babies are born in India, Bangladesh and western China. Despite the persistence of iodine deficiency in many parts of our world, we need to emphasize that major improvements in iodine nutrition have been made, and that our current efforts are making a difference, albeit more slowly than expected. 4

\section{The Health Impact of Endemic lodine Deficiency}

Iodine deficiency in humans and animals causes a wide spectrum of disorders, collectively known as Iodine Deficiency Disorders (IDD), affecting brain and skeletal growth and metabolism from conception until the end of life (Table 1). ${ }^{5}$ For quite some time, iodine deficiency was considered synonymous with endemic goiter because this manifestation is easily recognized, and in the child (but not in mature adults), it is readily reversed by iodine supplementation given to correct the deficiency (Figure 1).

Corresponding author: Creswell J. Eastman, $A M, M D$

Professor of Medicine, The Sydney Medical School, University of Sydney, Australia Vice Chairman and Regional Coordinator, Asia Pacific Region,

International Council for the Control of Iodine Deficiency Disorders (ICCIDD)

Principal, The Sydney Thyroid Clinic, Westmead Specialist Centre

P.O. Box 478 St. Leonards

NSW 2065 Australia

Tel. No.: +61294399396

Fax No.: +61294361501

E-mail:eastcie@ozemail.com.au 


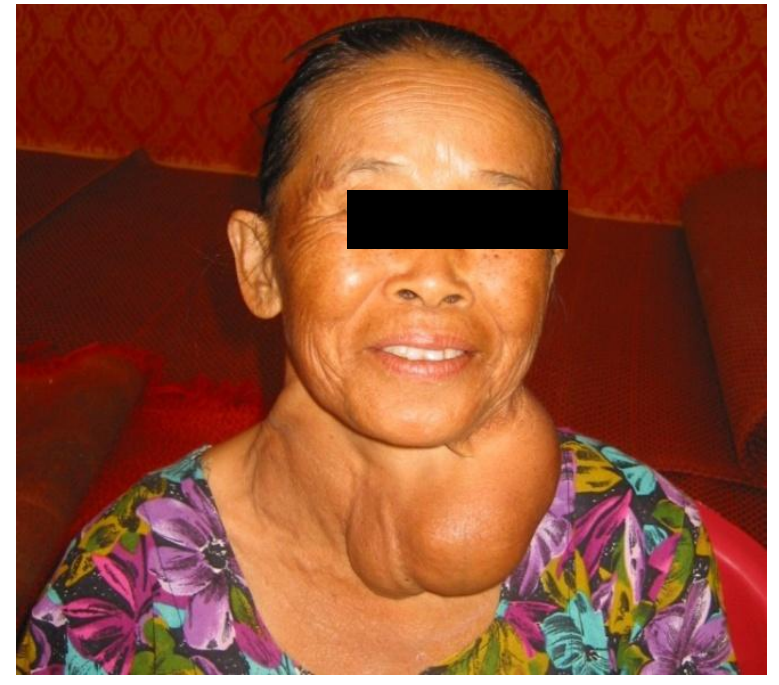

Figure 1. Mature age woman with large multinodular goiter after living all her life in a severe iodine deficiency region of Thailand.

One of the most puzzling questions has been how and when brain damage occurs from iodine deficiency. While congenital hypothyroidism, due mainly to underdevelopment or agenesis of the thyroid gland, is known to cause congenital myxedematous cretinism in the affected child, this clinical picture is not seen very often in populations where iodine deficiency is severe. In contrast, children born to mothers who were severely iodine deficient during pregnancy manifested a totally different clinical picture of a severe neurological disorder that has been termed neurological cretinism (Figure 2). This manifestation is very different from myxedematous cretinism. ${ }^{6}$ We now know that moderate to severe maternal iodine deficiency results in maternal and fetal hypothyroxinemia in the first and second trimesters, causing impaired development of the fetal central nervous system which, depending on severity, may vary from a mild decrease in IQ to severe neurological cretinism. ${ }^{6,7}$ Persistence of severe iodine deficiency and hypothyroidism during infancy causes myxedematous features in the child (Figure 3).

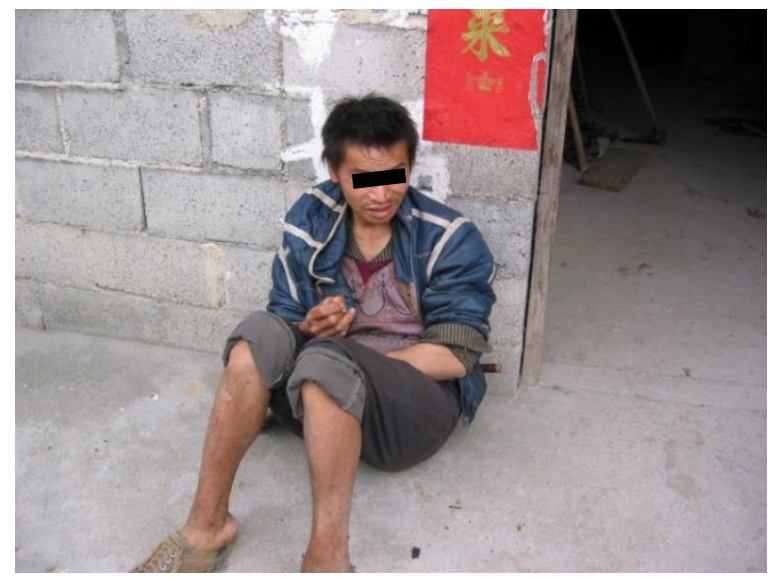

Figure 2. Adult male suffering from neurological cretinism in a severe iodine deficiency region of southwest China.

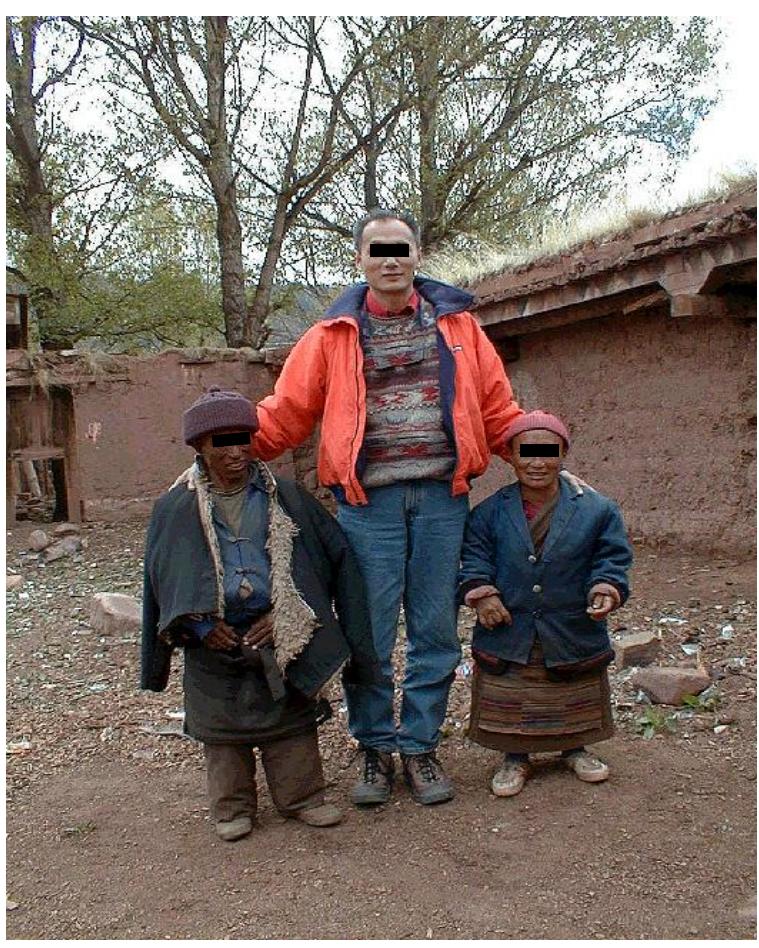

Figure 3. Two adult myxedematous cretins from a severe iodine defiency area in the Himalayan mountains in Tibet.

Table 1. Health consequences of iodine deficiency
disorders at different life stages*

It is commonly stated that iodine deficiency is the most common cause of preventable or impaired mental development worldwide. It has been well-documented that children born into families living in areas of moderate to severe iodine deficiency may lose up to 13.5 IQ points as a consequence of maternal iodine deprivation during pregnancy. ${ }^{8}$ It is this fact that makes iodine deficiency one of the more important and devastating non-communicable disorders in our world. The effects of IDD are a consequence of inadequate thyroid hormone production and action on hormone-sensitive target tissues. There is no evidence for an independent physiological function for iodine. In mammals, the sole function of iodine is to be incorporated into the thyroid hormone molecule through thyroid gland biosynthesis. 


\section{Social and Economic Impact}

It is well-established that moderate to severe iodine deficiency in a population has a negative impact on the health and well-being of that population, decreases productivity within the population, and is a barrier to socio-economic development. ${ }^{3}$ The International Child Development Steering Group has identified iodine deficiency as one of four key global health factors for impaired child development and where the need for intervention is most urgent. 9 Whenever the negative impact of micronutrient deficiencies on child development is examined, iodine deficiency usually figures at the top or near the top of the list of causes. Even economists attending the Copenhagen Consensus in 2008 ranked USI as third on their list of priorities to confront and overcome in their listing of the 10 biggest challenges in advancing global welfare. ${ }^{10}$ Unfortunately, hard evidence with good cost-benefit analyses from randomized, controlled trials is lacking. These studies need to be done to provide quantitative data on the correction of this nutritional deficiency.

\section{Indicators for Assessing lodine Deficiency and its Elimination}

The WHO has provided a number of criteria as guidance for the assessment of iodine deficiency and to determine whether IDD elimination goals have been met. ${ }^{11}$ Total goiter prevalence rate (TGR) in schoolchildren was the traditional method for assessing iodine deficiency in a population. While TGR provides information on the effect of long-term iodine deficiency in a community, it lags behind changes in iodine nutritional status and does not provide information on the current situation. ${ }^{3,4}$ It reflects what has happened in the past, but not what is happening in the present. As such, TGR is no longer used as a primary tool. For this reason, the definition of iodine deficiency is based primarily on population median urinary iodine concentration (MUIC) estimations. Approximately $90 \%$ of absorbed iodine is excreted in the urine within a day or two of absorption, and the MUIC is an excellent proxy indicator of iodine intake. The MUIC is usually determined from a statistical, representative sample of schoolchildren. ${ }^{11}$ While school-based surveys are the easiest to conduct, the major drawback to using iodine excretion in children as a proxy for assessing iodine deficiency in a population is that it is unable to assess iodine nutrition in the most vulnerable population groups, particularly pregnant and lactating women, infants and pre-school children. In the general population, the MUIC should be between 100 and $199 \mu \mathrm{g} / \mathrm{L}$, while in pregnant women it should be in the range of 150 to $249 \mu \mathrm{g} / \mathrm{L}$. Other biological indicators include monitoring of neonatal TSH levels, usually as part of national congenital hypothyroid screening programs; and more recently, measurement of serum thyroglobulin in blood spots taken from samples of the population. Household iodized salt usage is a useful indicator in rural populations, where most ingested salt is added at the household level and is not derived from processed food or salty condiments added to food.

\section{Changing Epidemiology of lodine Deficiency}

Within the Asia Pacific region, IDD has been recognized as a serious public health problem at various times in India, Pakistan, Bangladesh, Indonesia, Myanmar (Burma), Cambodia, Thailand, China (western provinces including Tibet), Mongolia, North Korea (DPRK), Laos, Malaysia, Papua New Guinea, East Timor and the Philippines (Table 2). This is not an exhaustive list, as national statistics are not available for most countries despite the WHA resolution that binds all member states to collect data and report back to the WHA. For this discussion we have excluded an analysis and discussion of sub-continental Asian countries such as India, Bangladesh and Pakistan. In some of these countries in the Asia Pacific region, serious iodine deficiency is limited to remotely located pockets of the population that are have limited access to iodized salt on a sustainable basis (Table 2).

Despite the difficulties, there has been considerable improvement in household iodized salt coverage in most of these countries over the past decade, giving hope to the realization of the goal of sustainable IDD control within the next decade. It should be noted that populations from Korea and Japan have liberal dietary iodine mainly from a high intake of iodine-containing seaweed products. ${ }^{12}$

Table 2. Current status of iodine nutrition in the Asia
\begin{tabular}{lll} 
Pacific region & & Unknown \\
\hline lodine sufficient & lodine deficient & Myanmar (Burma) \\
\hline People's Republic & Vietnam & Laos \\
of China & Indonesia (variable) & Most Pacific \\
Japan & Democratic People's & islands \\
South Korea & Republic of Korea (severe) & Papua New \\
Sabah and & Malaysia (variable) & Guinea \\
Sarawak & Philippines (variable) & Solomon Islands \\
Cambodia & Thailand (variable) & Samoa \\
Australia (recent) & \\
New Zealand & East Timor & \\
(recent) & India (variable) & \\
Taiwan & Bangladesh & \\
Mongolia & New Caledonia & \\
Fiji & Vanuatu & \\
Bhutan & & \\
Sri Lanka &
\end{tabular}

\section{Myths about lodine Deficiency}

There have been sporadic reports of goiter being endemic in the South Pacific, particularly in parts of Vanuatu, New Caledonia, Fiji, Samoa and some of the other smaller islands such as Tuvalu. Because many of the smaller countries in the Asia Pacific region are island states, with large expanses of coastline and presumed easy access to seafood, it has erroneously been assumed that iodine deficiency is not a significant endemic problem in the Pacific. ${ }^{3}$ As a consequence, little or no data on IDD has been collected in many of these poorer, smaller nations, but some of the best clinical research on IDD has been done in this part of the world. For example, data from 
surveys in the highlands of Papua New Guinea more than 50 years ago documented a cause-and-effect relationship between severe iodine deficiency in mothers and neurological cretinism in the offspring. A controlled therapeutic trial of iodized oil given to mothers early in pregnancy showed, for the first time, that endemic cretinism was a preventable disorder. ${ }^{13}$

A survey in Fiji in 1994 reported a goiter rate of just under $50 \%$ in schoolchildren and $15 \%$ in pregnant women. The MUIC of $26 \mu \mathrm{g} / \mathrm{L}$ in schoolchildren confirmed moderately severe iodine deficiency. ${ }^{14}$ This has now been addressed through a national iodized salt program. In a recent study on the island of Tanna, we were able to demonstrate moderate iodine deficiency in school-age children with a median urinary iodine excretion of $49 \mu \mathrm{g} / \mathrm{L}$ and increased thyroid volumes in $30 \%$ of the children, when compared with international reference ranges. ${ }^{15}$ It is still unknown how widespread and severe iodine deficiency is within the Pacific island nations, as studies have been few and far between, and we are lacking data other than sporadic observational records. Surveys are now underway in Samoa in the South Pacific and Guam in the North Pacific to determine the iodine nutritional status of these areas.

Another myth is that iodine deficiency only occurs in remote, mountainous areas populated by disadvantaged people who do not have access to a diverse and nutritious diet. In contrast, there has been widespread disregard for the crucial role of iodine nutrition in people living in advanced industrial nations. ${ }^{16}$ Illustrative examples of this neglect include Australia, New Zealand and the United Kingdom.3,4 Until the early 1990s, the populations of Australia and New Zealand were known to be iodine replete because of the widespread use of iodized salt, and bountiful supplies of iodine in milk and dairy products from iodine leaching into the milk from iodophore sanitizers used in the dairy industry from the 1960s onward. ${ }^{17}$ A national study of school-age children performed in Australia in 2003/2004 demonstrated mild iodine deficiency with a MUIC of $96 \mu \mathrm{g} / \mathrm{L}, 50 \%$ lower than data obtained from Australian children a decade before. ${ }^{18}$ Surveys in schoolchildren in New Zealand and the UK have yielded similar results and have caught public health authorities unaware of the development of iodine deficiency in their populations. ${ }^{19,20}$ The cause for the reemergence of iodine deficiency in these developed countries has been a consequence of changes in work practices in the dairy industry, where iodophores have been replaced by other non-iodine containing, less expensive sanitizers. ${ }^{21}$ This illustrates the point that optimal sustainable iodine nutrition cannot be based on adventitious sources of iodine in the diet.

\section{USI and Other Strategies to Meet Global lodine Requirements}

More than half a century has passed since the WHO first recommended iodization of all food salt for the population in areas where iodine deficiency was known to exist. Mandatory universal salt iodization (USI) represents the most effective public health strategy, where safety and efficacy can be assured, with a demonstrated need for the nutrient in the population. ${ }^{22}$ This strategy requires the iodization of all salt for human and animal consumption at a sufficient level-usually 20 to $40 \mathrm{mg}$ iodine per $\mathrm{kg}$ saltto ensure an adequate intake for all members of the population. However, USI must be underpinned by national legislation, as we know that voluntary systems are not sustainable strategies for eradicating iodine deficiency in a population. ${ }^{22}$ Salt is the ideal vehicle for iodine as it is an essential nutrient consumed consistently on a day-to-day basis. Iodization of salt is simple, inexpensive and cost-effective, amounting to less than one cent per day for an individual.

There are some fundamental differences implementing USI in the developing versus the developed world. In the developing world, most edible salt is consumed by direct addition to food being preserved or cooked and/or added to the food at the table. This is not true for many countries in the Indochina region (Thailand, Laos, Cambodia and Vietnam), where a good proportion of daily salt intake comes from salty condiments rather than the direct use of salt in the home. In contrast, in the developed world, most ingested salt-estimated in the vicinity of $80 \%$ of total daily salt-comes from processed food and is not added at the household level. Therefore, unless iodized salt is used in food processing and preparation, the quantity of iodine derived from the discretionary salt intake will be inadequate to sustain optimal iodine nutrition. Other sources will be necessary. Voluntary fortification of salt and other foods has many limitations and few benefits. ${ }^{22}$ Furthermore, the current worldwide push to decrease salt intake to prevent cardiovascular disease presents an entirely new challenge in addressing iodine deficiency in both developing and developed countries.

\section{lodine Supplementation}

The provision of iodine supplements to individuals or whole populations has long been a controversial issue, and is not generally recommended. Iodine supplementation is a useful but an expensive, inefficient and unsustainable strategy for preventing iodine deficiency. The major reasons for opposition to this strategy include poor population coverage, poor compliance within the population, expense, and lack of sustainability. ${ }^{22}$ It is now generally agreed that iodine supplementation has a place during pregnancy and while breastfeeding in populations where USI has not been implemented or has failed. ${ }^{23}$ Daily supplements of 150 to $250 \mu \mathrm{g}$ for all pregnant and lactating women have been recommended by the Endocrine Society, the American Thyroid Association, and the National Health and Medical Research Council in Australia. For pregnant and lactating women living in remote areas where daily iodine supplements are not practicable, depot preparations of iodized oil (containing 
$400 \mathrm{mg}$ of potassium iodate) are given orally on an annual basis. ${ }^{23}$ This is effective in preventing neurological cretinism, but the lack of randomized, controlled trials leave us with inadequate data to provide definitive statistics on efficacy and safety. Therefore, iodized oil should only be used in situations where daily iodine supplementation cannot be implemented.

\section{lodine Excess}

Iodine excess, like iodine deficiency, may also have adverse effects in a population. Complications include goiter, hyperthyroidism, hypothyroidism, and an increased prevalence of thyroid autoimmunity. Iodine excess disorders have been described in China and Japan, but are otherwise rare in the Asia-Pacific region. ${ }^{24,25}$ While the adverse effects of iodine deficiency far outweigh the adverse effects of iodine excess, programs designed to eradicate iodine deficiency should seek to establish optimal iodine nutrition throughout the whole population, and not operate on the basis that because iodine is "good for you, more is better."

\section{What are the lessons that we have learned in these developing countries?}

\section{Lessons Learned}

We have learned the following from our studies and observations on developing countries:

1. There is a lack of national data on the extent and severity of iodine deficiency in most countries in the Asia Pacific region, because representative surveys in the population have not been undertaken.

2. Framing the message of iodine deficiency around brain damage, loss of IQ and impaired mental and physical development is far more powerful and persuasive than advocating iodine prophylaxis programs for endemic goiter.

3. Advocacy at the government level is essential to influence those that have the power to make decisions. IDD is not simply a public health problem, but a "whole of government" issue affecting social and economic development. Obtaining and maintaining high-level political commitment to eliminating IDD is essential.

4. USI (mandatory fortification of all edible salt with iodine) must be accepted at a national level as the most appropriate vehicle for normalizing iodine nutrition within a community. Acceptance of USI must be followed by implementation of legislation and regulations underpinning this initiative.

5. Multi-sectoral involvement is a prerequisite for success. The salt industry is as an important player as the health sector in achieving USI, and must accept responsibility to ensure the supply of iodized salt.
6. Education of the public is necessary to create demand for iodized salt and sustainability of optimal iodine intake.

7. A vital component of successful outcome is the implementation of a program for regular monitoring of the iodine intake of the population, and the quality assurance of iodized salt at the production and retail levels, with mandatory public reporting of these data.

8. Where iodized salt cannot be provided to all citizens, particularly children and women of childbearing age, an iodized oil supplementation program should be employed as an interim strategy. This is an effective way of protecting the newborn, and the growth and development of infants and children.

In summary, iodine deficiency remains one of the most prevalent and devastating non-communicable disorders in our world, with the potential to profoundly threaten the health and socio-economic development of almost onethird of the population on our planet. Within the Asia Pacific region, iodine deficiency is highly prevalent. More attention is needed in gathering national data to determine its prevalence and to formulate effective public health policy for the development and implementation of sustainable IDD elimination programs.

\section{References}

1. Andersson M, Karumbunathan V, Zimmermann MB. Global iodine status in 2011 and trends over the past decade. J Nutr 2012;142(4):74450 .

2. World Health Organization. WHA 58.24 Sustaining the elimination of iodine deficiency disorders. In: Fifty-Eighth World Health Assembly Resolutions and Decisions Annex WHA58/2005/REC/1. Geneva: World Health Organization, 2005. http://apps.who.int/gb/ ebwha/pdf_files/WHA58-REC1/english/A58_2005_REC1-en.pdf.

3. Li M, Eastman CJ. The changing epidemiology of iodine deficiency. Nat Rev Endocrinol 2012;8(7):434-40.

4. Zimmermann MB, Andersson M. Assessment of iodine nutrition in populations: Past, present and future. Nutr Rev 2012;70(10):553-70.

5. Hetzel BS. Iodine deficiency disorders (IDD) and their eradication. Lancet 1983;2(8359):1126-9.

6. Halpern JP, Boyages SC, Maberly GF et al. The neurology of endemic cretinism. A study of two endemias. Brain 1991;114(Pt 2):825-41.

7. Boyages SC, Halpern JP, Maberly GF et al. A comparative study of neurological and myxedematous endemic cretinism in western China. J Clin Endocrinol Metab 1988;67(6):1262-71.

8. Qian M, Wang D, Watkins WE et al. The effects of iodine on intelligence in children: A meta-analysis of studies conducted in China. Asia Pac J Clin Nutr 2005;14(1):32-42.

9. Walker SP, Wachs TD, Gardner JM et al. Child development: Risk factors for adverse outcomes in developing countries. Lancet 2007;369(9556):145-57.

10. Horton S, Mannar V, Wesley A. Best Practice Paper: Food fortification with iron and iodine. Denmark: Copenhagen Consensus Centre, 2008. http://www.copenhagenconsensus.com/Default.aspx?ID=1303

11. World Health Organization. Assessment of iodine deficiency disorders and monitoring their elimination: A guide for programme managers. $3^{\text {rd }}$ ed. Geneva: World Health Organization, 2007. http://whqlibdoc.who.int/publications/2007/9789241595827_eng.pdf

12. Fuse $Y$, Ohashi $Y$, Yamaguchi $S$ et al. Iodine status of pregnant and postpartum Japanese women: Effect of iodine intake on maternal and neonatal thyroid function in an iodine- sufficient area. J Clin Endocrinol Metab 2011;96(12):3846-54. 
13. Pharoah PO, Buttfield IH, Hetzel BS. Neurological damage to the fetus resulting from severe iodine deficiency during pregnancy. Lancet 1971;1(7694):308-10.

14. Kumar B, Moriarty H, Khan N et al. Progress in the Fijian iodine supplementation program. Network for sustained elimination of iodine deficiency (online). http://www.iodinenetwork.net/ documents/salt-sym-2009

15. Li M, McKelleher $\mathrm{N}$, Moses $\mathrm{T}$ et al. Iodine nutritional status of children on the island of Tanna, Republic of Vanuatu. Public Health Nutr 2009;12(9):1512-8.

16. Zimmermann MB. Iodine deficiency in industrialized countries. Clin Endocrinol (Oxf) 2011;75(3):287-8

17. Eastman CJ. Where has all our iodine gone? Med J Aust 1999;171(9):455-6.

18. Li M, Eastman CJ, Waite KV et al. Are Australian children iodine deficient? Results of the Australian National Iodine Nutrition Study. Med J Aust 2006;184(4):165-9.

19. Skeaff SA, Thomson CD, Gibson RS. Mild iodine deficiency in a sample of New Zealand schoolchildren. Eur J Clin Nutr 2002;56(12):1169-75.

20. Vanderpump MP, Lazarus JH, Smyth PP et al. Iodine status of UK schoolgirls: A cross-sectional survey. Lancet 2011;377(9782):2007-12.

21. Li M, Waite KV, Ma G et al. Declining iodine content of milk and reemergence of iodine deficiency in Australia. Med J Aust 2006;184(6):307.

22. Eastman CJ, Jooste P. Current challenges in meeting global iodine requirements. In: Bhutta ZA, Hurrell RF, Rosenberg IH, eds. Meeting micronutrient requirements for health and development. Nestle Nutrition Institute Workshop Series Volume 70. Basel: Karger, 2012.

23. WHO Secretariat, Andersson M, de Benoist B et al. Prevention and control of iodine deficiency in pregnant and lactating women and in children less than 2-years-old: Conclusions and recommendations of the Technical Consultation. Public Health Nutr 2007;10(12A):1606-11.

24. Li M, Liu DR, Qu CY et al. Endemic goitre in central China caused by excessive iodine intake. Lancet 1987;2(8553):257-9.

25. Konno N, Makita H, Yuri K et al. Association between dietary iodine intake and prevalence of subclinical hypothyroidism in the coastal regions of Japan. J Clin Endocrinol Metab 1994;78(2):393-7.

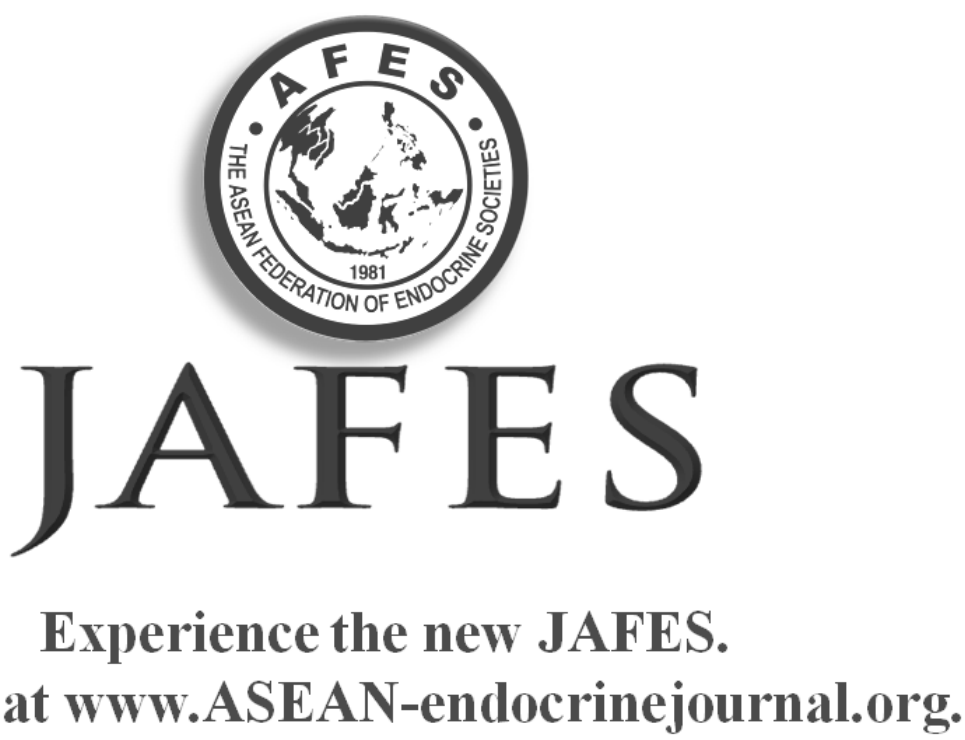

